\title{
Lung volume assessments in normal and surfactant depleted lungs: agreement between bedside techniques and $\mathrm{CT}$ imaging
}

\author{
Gergely Albu' ${ }^{1}$ Ferenc Petak ${ }^{2}$, Tristan Zand ${ }^{3}$, Magnus Hallbäck ${ }^{4}$, Mats Wallin ${ }^{4}$ and Walid Habre ${ }^{1,5^{*}}$
}

\begin{abstract}
Background: Bedside assessment of lung volume in clinical practice is crucial to adapt ventilation strategy. We compared bedside measures of lung volume by helium multiple-breath washout technique (EELV $\left.V_{M B W_{1}, \mathrm{He}}\right)$ and effective lung volume based on capnodynamics (ELV) to those assessed from spiral chest CT scans (EELV $\left.V_{C T}\right)$ under different PEEP levels in control and surfactant-depleted lungs.

Methods: Lung volume was assessed in anaesthetized mechanically ventilated rabbits successively by measuring i) ELV by analyzing $\mathrm{CO}_{2}$ elimination traces during the application of periods of 5 consecutive alterations in inspiratory/ expiratory ratio (1:2 to 1.5:1), ii) measuring EELV $V_{M B W, H e}$ by using helium as a tracer gas, and iii) $E E L V_{C T}$ from $C T$ scan images by computing the normalized lung density. All measurements were performed at PEEP of 0,3 and $9 \mathrm{cmH}_{2} \mathrm{O}$ in random order under control condition and following surfactant depletion by whole lung lavage.

Results: Variables obtained with all techniques followed sensitively the lung volume changes with PEEP. Excellent correlation and close agreement was observed between EELV $V_{M B W, H e}$ and $E E L V_{C T}(r=0.93, p<0.0001)$. ELV overestimated $E E L V_{M B W, H e}$ and $E E L V_{C T}$ in normal lungs, whereas this difference was not evidenced following surfactant depletion. These findings resulted in somewhat diminished but still significant correlations between ELV and EELV $V_{C T}$ $(r=0.58, p<0.001)$ or $\operatorname{EELV}_{\text {MBW,He }}(0.76, p<0.001)$ and moderate agreements.

Conclusions: Lung volume assessed with bedside techniques allow the monitoring of the changes in the lung aeration with PEEP both in normal lungs and in a model of acute lung injury. Under stable pulmonary haemodynamic condition, ELV allows continuous lung volume monitoring, whereas EELV $\mathrm{MBW}_{\mathrm{H}, \mathrm{He}}$ offers a more accurate estimation, but intermittently.
\end{abstract}

Keywords: Effective lung volume, Capnodynamics, Gas exchange, Lung mechanics, Lung injury

\section{Background}

The history of medicine has been marked by a spectacular evolution of mechanical ventilation and its inevitable benefit in providing life support both in anaesthesia and critical care management. Nevertheless, one of the main consequences of mechanical ventilation with positive intermittent pressure in the airways is the loss of static lung volumes subsequent to atelectasis, intra-alveolar fluid

\footnotetext{
* Correspondence: Walid.Habre@hcuge.ch

'Pathophysiological Experimental Platform, Department of Anaesthesiology, Pharmacology and Intensive Care, University of Geneva, 1 Rue Michel Servet, CH-1205 Geneva, Switzerland

${ }^{5}$ Paediatric Anaesthesia Unit, Geneva Children's Hospital, University Hospitals of Geneva, 6, Rue Willy Donzé, CH-1205 Geneva, Switzerland

Full list of author information is available at the end of the article
}

accumulation, interstitial edema formation, and surfactant damage. In order to prevent these deleterious effects on the lung, new concepts of mechanical ventilation target an open lung ventilation strategy involving protective ventilation modes with low tidal volumes, regular alveolar recruitments and maintenance of optimal positive end-expiratory pressure (PEEP). In order to optimize ventilation strategy, it is essential to include lung volume assessment as part of ventilation monitoring.

Assessment of lung volumes is widespread in the respiratory medicine; however, there are only few techniques that can be implemented at bed side to optimize the ventilation strategy. Static lung volume, such as the endexpiratory lung volume (EELV) in ventilated patients is 
assessed by analyzing the concentration changes of an inert gas during wash-in/wash-out maneuvers [1-4]. A recently developed alternative to EELV is the effective lung volume (ELV), which is based on a continuous breath-by-breath analysis of the carbon dioxide after alteration of the inspiratory pattern [5]. We showed that ELV detects lung derecruitment and recruitment [6] with the additional advantage of continuous monitoring of the ventilated patient.

Image processing to quantify lung volume from computed tomography CT scans has been largely used as a reference method in patients with acute lung injury [7-9]. However, it is technically demanding, time consuming and involves radiation exposure. CTs are therefore inappropriate for routine clinical practice. Bedside monitoring of EELV may provide similar insight into the lung volume available for gas exchange. Comparative results for these different available approaches for quantification of the aerated lung areas are not available.

We aimed to relate lung volume indices obtained from bedside techniques to those computed by chest $\mathrm{CT}$ image analyses. Furthermore, we aimed to establish the relationships between static lung volume outcome variables obtained from healthy lungs and in a model of acute lung injury by surfactant depletion.

\section{Methods}

\section{Animal preparation}

The experimental protocol was approved by the institutional ethics committee for experimental research of the University of Geneva and animal welfare committee (Office Véterinaire Cantonal de Genève registration number 1051/ 3609/1, Geneva, Switzerland). Eight adult New Zealand white rabbits (weighing 2.4-3.1 kg) were anaesthetized by an intramuscular injection of xylazine $(5 \mathrm{mg} / \mathrm{kg}$ ), followed by an iv injection of midazolam $(1 \mathrm{mg} / \mathrm{kg})$ and pentobarbital sodium $(30 \mathrm{mg} / \mathrm{kg}$ ) via an ear vein. Following tracheotomy, an endotracheal tube (4 mm i.d., Portex ${ }^{\oplus}$, Smiths Medical, Kent, UK) was inserted into the distal trachea. Mechanical ventilation was started in volume controlled mode (Servo-i Maquet Critical Care, Solna Sweden equipped with an additional software) with a fixed respiration rate of 40 breaths/min and inspired oxygen fraction $\left(\mathrm{FiO}_{2}\right)$ of 0.5 . Tidal volume was set to $7-8 \mathrm{ml} / \mathrm{kg}$ in order to target an end-tidal $\mathrm{CO}_{2}\left(\mathrm{E}_{\mathrm{TCO} 2}\right)$ of $5.5-6 \%$. Maintenance of anesthesia was assured by a continuous iv infusion of midazolam $(1 \mathrm{mg} / \mathrm{kg} / \mathrm{h})$ and fentanyl $(100 \mu \mathrm{g} /$ $\mathrm{kg} / \mathrm{h}$ ) via the ear vein. Muscle relaxation was achieved by atracurium $(0.5-1.0 \mathrm{mg} / \mathrm{kg} / \mathrm{h})$ after ensuring adequate anesthesia and analgesia level. Airway pressure, heart rate and rectal temperature were displayed and stored on a computer at a sampling rate of $50 \mathrm{~Hz}$ via an analogue/ digital interface converter (Biopac, Santa Barbara, CA, USA).

\section{Measurement of EELV by multiple breath washout technique}

A technique using multiple-breath wash-in/wash-out maneuvers with helium $(\mathrm{He})$ as tracer gas was used to measure $\mathrm{EELV}_{\mathrm{MBW}, \mathrm{He}}$, as detailed previously $[1,10]$. Briefly, an ultrasonic flow meter (Spiroson Scientific; ECO Medics AG, Dürnten, Switzerland) was instrumented between the endotracheal tube connector and the ventilator circuit to assess changes in molar mass of the respiratory gas. A recording at steady-state end-inspiratory concentration of $\mathrm{He}$ at 4-5\% was established. by washing-in the inert gas into the ventilatory circuit. The He tracer gas flow was interrupted, and the washout of the tracer gas was recorded. $\mathrm{EELV}_{\mathrm{MBW}, \mathrm{He}}$ was calculated from the changes in the He concentration during the wash-out phase using the software, (Spiroware, V1.4.3, ECO Medics AG, Dürnten, Switzerland) as:

$$
E E L V_{M B W, H e}=\frac{\text { net volume of inert gas exhaled }}{C_{\text {start }}-C_{\text {end }}}
$$

where $\mathrm{C}_{\text {start }}$ and $\mathrm{C}_{\text {end }}$ are the concentrations of $\mathrm{He}$ at end-tidal volume at the start and at the end of the $\mathrm{He}$ wash-out recording, respectively. The multiple breath washout technique also allows the assessment of the lung clearance index (LCI) as an indicator of ventilation heterogeneity. LCI was calculated as the number of lung volume turnovers required to diminish the He concentration to $1 / 40$ th of the starting value [11]. The instrumental dead space $(3.8 \mathrm{ml})$ was subtracted from the reported EELV $_{\mathrm{MBW}, \mathrm{He}}$ values.

\section{Assessment of ELV}

Ventilation airflow and changes in $\mathrm{CO}_{2}$ concentration were recorded by ordinary Y-piece flow sensor and a main stream capnometer of the Servo-i ventilator. Flow and $\mathrm{CO}_{2}$ signals were digitized by a computer via an RS232 port. Analyses of the flow and $\mathrm{CO}_{2}$ traces were performed by using a special purpose software application written in Matlab ${ }^{\text {TM }}$ (Mathworks, Natick, Massachusetts, USA).

Breath-by-breath analysis of the $\mathrm{CO}_{2}$ changes after alteration of the inspiratory pattern was used to determine the effective lung volume that takes part in gas exchange, as detailed previously [6]. Briefly, the inspiratory pause was varied to introduce 5 consecutive alterations in inspiratory/expiratory ratio ( $1: 2$ to $1.5: 1)$ to the normal mechanical ventilation. Resulting from this modified breathing pattern, a variation in end-tidal carbon dioxide $\left(\mathrm{E}_{\mathrm{TCO} 2}\right)$ of about $0.5-1.0 \mathrm{kPa}$ develops. The differential Fick's method can be used continuously without attaining a new second steady-state condition by measuring and calculating the dynamic transient changes in $\mathrm{E}_{\mathrm{TCO} 2}$ and $\mathrm{CO}_{2}$ elimination rate [12]. 
An equation describing the mole balance in the lungs was used to calculate ELV:

$$
E L V \cdot\left(F_{A} C O_{2}^{n}-F_{A} C O_{2}^{n-1}\right)=Q_{c} \cdot \Delta t^{n} \cdot\left(C_{\nu} C O_{2}-C_{c} C O_{2}^{n}\right)-V T_{C O 2^{n}}
$$

where ELV is the effective lung volume containing $\mathrm{CO}_{2}$ at end of expiration, $\mathrm{n}$ is the current and $\mathrm{n}-1$ is the previous breath, $\mathrm{F}_{\mathrm{A}} \mathrm{CO}_{2}$ is the alveolar $\mathrm{CO}_{2}$ fraction at end of expiration (approximated by $\mathrm{E}_{\mathrm{TCO} 2}$ ), $\mathrm{Q}_{\mathrm{c}}$ is the effective pulmonary blood flow, $\mathrm{C}_{\mathrm{v}} \mathrm{CO}_{2}$ is the venous $\mathrm{CO}_{2}$ content $\left[\mathrm{L}_{\text {gas }} / \mathrm{L}_{\text {blood }}\right], \mathrm{C}_{\mathrm{c}} \mathrm{CO}_{2}{ }^{\mathrm{n}}$ is the lung capillary $\mathrm{CO}_{2}$ content (calculated from $\mathrm{E}_{\mathrm{TCO} 2}$ ), $\mathrm{VT}_{\mathrm{CO} 2}{ }^{\mathrm{n}}$ is the volume of $\mathrm{CO}_{2}$ eliminated by the current $\left(\mathrm{n}^{\text {th }}\right)$ breath and $\Delta \mathrm{t}^{\mathrm{n}}$ is the time for the current breath cycle time. The left side of the equation yields the difference in end-tidal $\mathrm{CO}_{2}$ content in the lung between two breaths. The first term on the right side describes the circulatory supply of $\mathrm{CO}_{2}$ in the alveolar compartment between two breaths. The $\mathrm{CO}_{2}$ content in the lung capillary blood, $\mathrm{C}_{\mathrm{c}} \mathrm{CO}_{2}$, is calculated from the alveolar $\mathrm{CO}_{2}$ fraction using the dissociation curve suggested by Capek et al. [13]. The second term on the right side is the amount of carbon dioxide eliminated from the lungs by the $\mathrm{n}^{\text {th }}$ tidal volume.

To determine the unknown variables, a new equation is created for each of the 10 breaths in the sequence. Thus, 10 breaths create 10 equations with three unknown variables. The equation system can be solved by optimizing the fit between observed $\mathrm{F}_{\mathrm{A}} \mathrm{CO}_{2}$ data and calculated $\mathrm{F}_{\mathrm{A}} \mathrm{CO}_{2}$ according to the balance equation above. Thus, it is possible to determine ELV, which is the gas volume in the lung at end-expiration including the airway volume up to the site of the $\mathrm{CO}_{2}$-sensor.

\section{Assessment of EELV by CT image processing}

The CT scans were taken in the supine position using a high resolution CT scanner (GE LightSpeed VCT 64, Waukesha, Wisconsin, USA). The scanning time was fixed on $2.5 \mathrm{~s}$, helical full in $0.4 \mathrm{~s}$. The field of view was $20 \mathrm{~cm}$ and the CT-scanning was set at energy of $100 \mathrm{kV}$, and an automatic electrical current between 10 to $200 \mathrm{~mA}$, with a signal-to-noise ratio of 10 . The image thickness was $0.625 \mathrm{~cm}$ with identical image interval. A standard high resolution reconstruction algorithm for the lung was employed. During the scanning periods, the mechanical ventilation was suspended at end-expiration. No contrast medium was injected.

The pulmonary volumes were calculated on the CT scan by manual surface delineation of pulmonary tissue on the transverse slices multiplied by slice thickness. As there are many interstitial structures and some focal infiltrates and hypoventilation beyond the CT resolution, the volume was compensated to better approximate actual air content by pondering the total volume by a factor based on the mean Hounsfield Unit measurement of the same pulmonary area. The pondering factor was calculated based on the measurement of air outside the actual body (approximately $-1000 \mathrm{HU}$ ), and that all other tissues density can be well evaluated by a ROI on the hilum (approximately $0 \mathrm{HU}$ ), and the linear nature of $\mathrm{HU}$ density characteristics.

\section{Experimental protocol}

After the surgical preparation, the rabbits were ventilated with PEEP of $3 \mathrm{cmH}_{2} \mathrm{O}$ and a 10-15 min period was allowed for the animals to reach a steady-state condition in the systemic hemodynamic and ventilation parameters. The "pressure history" was then standardized by superimposing inspiratory cycles to reach a peak pressure of $30 \mathrm{cmH}_{2} \mathrm{O}$. The first PEEP level was then set (either 0,3 or $9 \mathrm{cmH}_{2} \mathrm{O}$ ) and continuous measurement of ELV with the Servo-i ventilator was then performed for 10 minutes before recording its steady-state value (Figure 1). Two minutes later, two multiple breath washin/wash-out maneuvers with $\mathrm{He}$ were performed to assess EELV $\mathrm{MBW}_{\mathrm{He}}$. These lung volume measurements were followed by the chest CT imaging. The same sequence of measurements including the standardization of the "pressure history" was then repeated twice while setting the PEEP to the other two levels in random order. After completing the lung volume recordings in the healthy lungs, whole lung lavage was performed by instilling warm $0.9 \%$ saline $\left(15 \mathrm{ml} / \mathrm{kg}\right.$ at $\left.37^{\circ} \mathrm{C}\right)$ into the endotracheal cannula. The instilled fluid was then withdrawn by gentle manual suctioning. This surfactant depletion procedure was repeated twice with the animal being reconnected and ventilated between the manoeuvres.

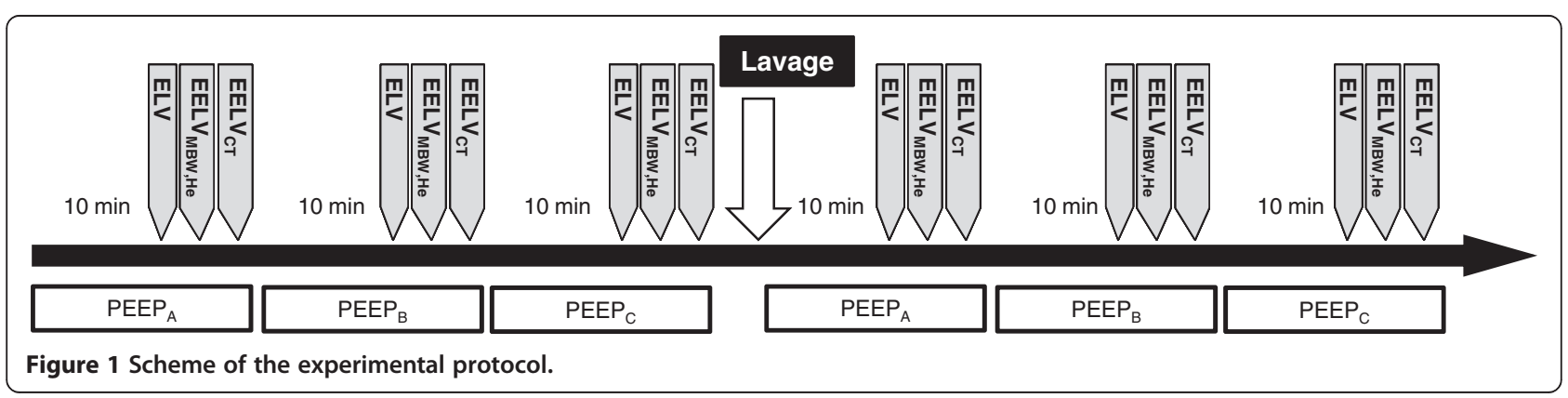


After lavage, $\mathrm{FiO}_{2}$ was increased to $80 \%$, the standardisation manoeuvre was performed as detailed above and the lung volume measurements were repeated while PEEP levels of 0,3 and $9 \mathrm{cmH}_{2} \mathrm{O}$ were maintained in random order.

\section{Statistical analyses}

The scatters in the variables were expressed by the SE values. Normality of the data was checked with the Kolgomorov-Smirnov test with Lilliefors correction. Two-way repeated measures analysis of variance (ANOVA) was used with the PEEP level as the within subject factor and the lung volume assessment method as the between subject factor to establish the differences between the assessment methods and PEEP. Pairwise comparisons were performed on estimated marginal means by taking into account the presence or absence of interaction; the p-values were corrected by the Holm-Sidak method. Correlation analyses were performed by using Pearson statistical tests. A modified polar plot representation of the Bland-Altman analysis [14] that allows more elaborate trend assessment was performed to determine the agreement between different lung volume indices $[15,16]$. In this presentation, the angle between the radial vector and the horizontal axis represents the magnitude of difference between the corresponding variables, while the distance from the center represents the mean of the two corresponding variables. Statistical tests were carried out with the significance level set at $\mathrm{p}<0.05$. SigmaPlot software package (version 11, Chicago, IL, USA) was used in the analyses.

\section{Results}

Lung volume indices obtained at different PEEP levels in healthy and surfactant-depleted lungs are demonstrated in Figure 2. As expected, increasing PEEP led to elevations in all end expiratory lung volume variables before $(\mathrm{p}<0.001)$ and after whole lung lavage $(\mathrm{p}<0.001)$. In the healthy lungs, no statistically significant differences were evident between EELV $\mathrm{MBW}_{\mathrm{Me}}$ and $\mathrm{EELV}_{\mathrm{CT}}$ at any PEEP levels. However, ELV was significantly greater than either EELV variable in healthy lung at low PEEP levels $(\mathrm{p}<0.001)$ while this difference was not obvious during the maintenance of a PEEP of $9 \mathrm{cmH}_{2} \mathrm{O}$. No statistically significant difference was detectable between the lung volume variables after lung lavage at any PEEP level.

Figure 3 depicts changes in the LCI with PEEP under baseline conditions and after lung lavage. Surfactant depletion elevated LCI at all PEEP levels $(\mathrm{p}<0.001)$. Increasing PEEP resulted in significant decreases in the LCI $(p<0.001)$; these reductions were more pronounced for the lungs after lavage.

The relationship between the lung volume indices obtained by the three different measurements techniques are demonstrated on Figure 4. There were statistically significant correlations between each pair of variables $(\mathrm{p}<0.001)$ with strongest associations between $\operatorname{EELV}_{\mathrm{MBW}, \mathrm{He}}$ and $\operatorname{EELV}_{\mathrm{CT}}(\mathrm{r}=0.93, \mathrm{p}<0.0001)$. The correlations between the ELV and the other two lung volume indices EELV $_{\mathrm{CT}}$ and $\left.\operatorname{EELV}_{\mathrm{MBW}, \mathrm{He}}\right)$ were somewhat weaker $(\mathrm{r}=0.58$ and $\mathrm{r}=$ $0.76)$, but still highly significant ( $\mathrm{p}<0.0001)$.

Figure 5 summarizes the degrees of agreements between each pair of lung volume variables measured on polar plots. The mean value of the variable pairs are plotted as a distance from the centre of the polar plot, while the angle between the radial vector and the horizontal axis represents the differences between each pair of variables. Excellent agreement was found between $\mathrm{EELV}_{\mathrm{MBW}, \mathrm{He}}$ and

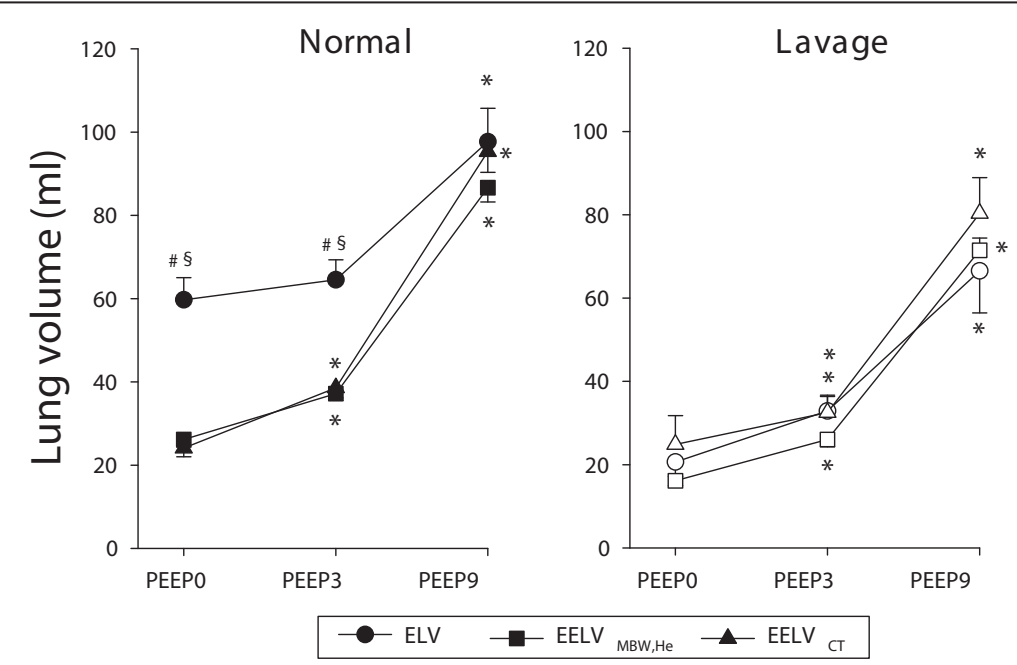

Figure 2 Lung volume variables obtained at different PEEP levels in normal (closed symbols) and surfactant depleted lungs (open symbols). Circles denote the mean values for effective lung volume (ELV) obtained by capnodynamics; squares represent mean values obtained by helium multiple breath washout technique $\left(\mathrm{EELV}_{\mathrm{MBW}, \mathrm{He}}\right)$; and triangles represent mean values for lung volume computed from chest $\mathrm{CT}$-scans $\left(\right.$ EELV $\left._{C T}\right)$. * $p<0.05$ vs. PEEPO, \#: $p<0.05$ vs. EELV ${ }_{M B W, H e}$ within a PEEP, $\S: p<0.05$ vs. EELV $V_{C T}$ within a PEEP. 


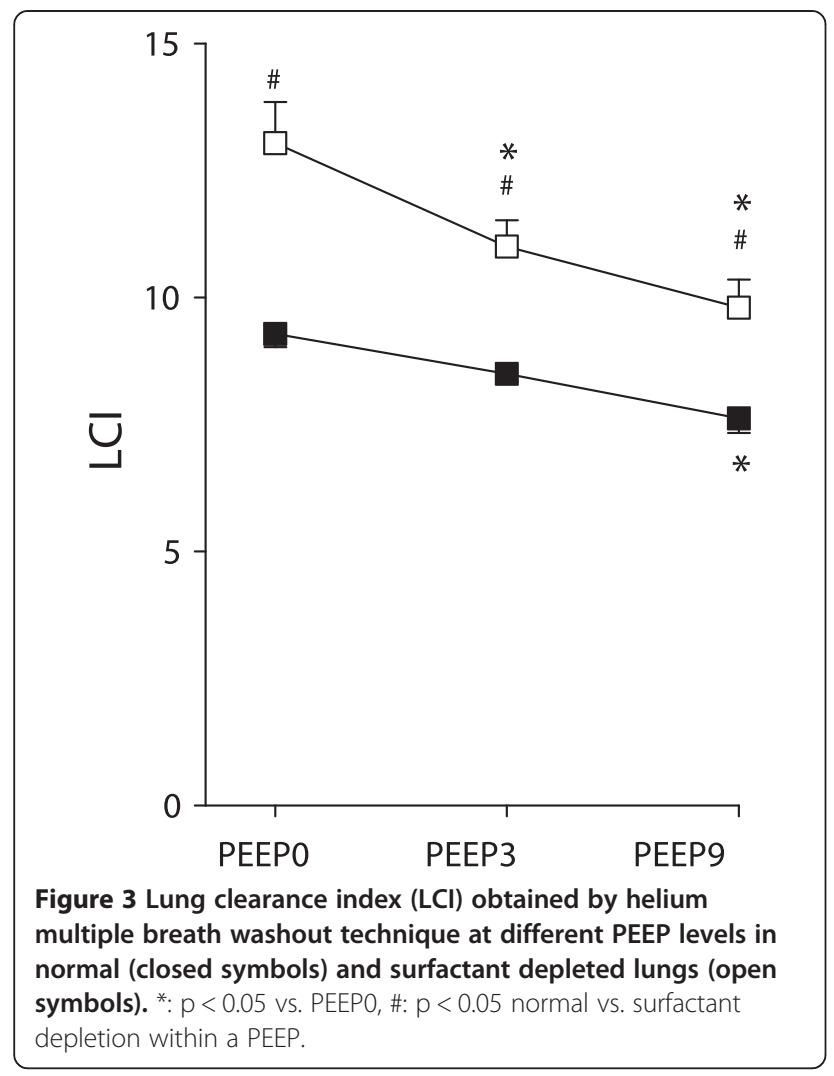

EELV $_{\mathrm{CT}}$ in the normal lungs with mean polar angle of 2.4 degrees and radial limits of agreement of -15.5 and 20.3 degrees (based on the 95\% confidence interval limits). This close agreement remained after lavage with mean polar angle of 8.0 degrees and agreement limits of -19.6 and 35.6 degrees. There was a weaker agreement between the ELV and the other two lung volume variables, with the mean polar angles of $-23.5\left(\mathrm{EELV}_{\mathrm{MBW}, \mathrm{He}}\right)$ and -21.1 $\left(\mathrm{EELV}_{\mathrm{CT}}\right)$ degrees and radial limits of agreement of -58.9 and $11.8\left(\operatorname{EELV}_{\mathrm{MBW}, \mathrm{He}}\right)$, and -69.3 and 27.1 degrees $\left(E_{C L V} V_{C T}\right)$, respectively, under baseline condition. Surfactant depletion improved these agreements with mean polar angles of -2.1 (EELV $\left.V_{\mathrm{MBW}, \mathrm{He}}\right)$ and $5.8\left(\mathrm{EELV}_{\mathrm{CT}}\right)$ degrees and radial limits of agreement of -34.1 and 29.8 $\left(\mathrm{EELV}_{\mathrm{MBW}, \mathrm{He}}\right)$, and -45.6 and 57.4 degrees $\left(\mathrm{EELV}_{\mathrm{CT}}\right)$, respectively.

\section{Discussion}

The results of the present study demonstrate that bedside assessment of lung volume offers a meaningful alternative to those obtained by CT scan imaging. Both bedside lung volume assessments were able to follow the increased lung aeration with elevating PEEP and the development of airway closures following surfactant depletion. This study also evidenced an excellent value of the lung volume measurement performed by inert gas multiple breath washout technique both in normal lungs and in a model of acute lung injury. Conversely, effective lung volume available for gas exchange assessed from the analyses of the expired $\mathrm{CO}_{2}$ exhibited greater scatters in the agreements with the other two indices.

We adopted the technique of surfactant depletion by performing whole lung lavage as a model of acute lung injury. The pathogenesis of this severe pulmonary disorder is far more complex then the loss of surfactant function. Nonetheless, the present model mimics lung collapsibility and the loss or regional lung ventilation with increased heterogeneity, particularly at low PEEP levels [17]. Atelectasis development was evidenced from the marked and significant decreases in $\operatorname{EELV}_{\mathrm{MBW}, \mathrm{He}}(-38 \pm 5.3 \%, \mathrm{p}<0.005)$ and ELV $(-65 \pm 4.2 \%, \mathrm{p}<0.001)$ at PEEP 0 . The lavageinduced changes in $\mathrm{EELV}_{\mathrm{CT}}$ were less obvious, since lung volume variable includes all aerated structures including those with trapped air [17]. To avoid time effects in our findings, the order of PEEP was randomized within a set of recordings. However, the three different lung volume readings were always performed in the same sequence. None of the measurements techniques required altering the ventilation pressures beyond the normal range. The only change in the ventilation pattern was necessary to record ELV, but the short inspiratory pause did not affect the peak or mean airway pressures markedly and thus, it was unlikely to bias our findings.

An important finding of the present study is that while ELV follows the expected trend with increasing PEEP, it systematically overestimates the EELV at low PEEP levels in the healthy lungs (Figure 2). To provide a plausible explanation for this apparent discrepancy, the fundamental differences between ELV and EELV estimates warrant consideration. ELV reported in the present study reflects all compartments contributing to the $\mathrm{CO}_{2}$ content in the lung including the alveoli, lung tissue and lung capillary blood. While the individual contribution of these compartments is not straightforward to assess in the present study, previous investigations established a correction factor of 55\% at PEEP 0 in healthy lungs to adjust for both blood and lung tissue $\mathrm{CO}_{2}$ content [18]. Indeed, implementation of this correction factor at PEEP 0 reveals excellent agreements between the corrected ELV $(26.9 \pm 2.4$ $\mathrm{ml})$, the $\operatorname{EELV}_{\mathrm{MBW}, \mathrm{He}}(26.2 \pm 1.8 \mathrm{ml})$ and the $\operatorname{EELV}_{\mathrm{CT}}$ data $(24.1 \pm 2.1 \mathrm{ml})$. Nevertheless, a systematic application of such a correction factor during the maintenance of different PEEP levels and in injured lungs would be erroneous, since both PEEP and surfactant depletion affect markedly the capillary blood in the alveolar wall and the parenchymal contribution to the total $\mathrm{CO}_{2}$ [19]. A PEEPdependent correction factor taking into account the capillary blood volume and the lung tissue contribution in healthy and injured lungs may be a subject for further investigations. 

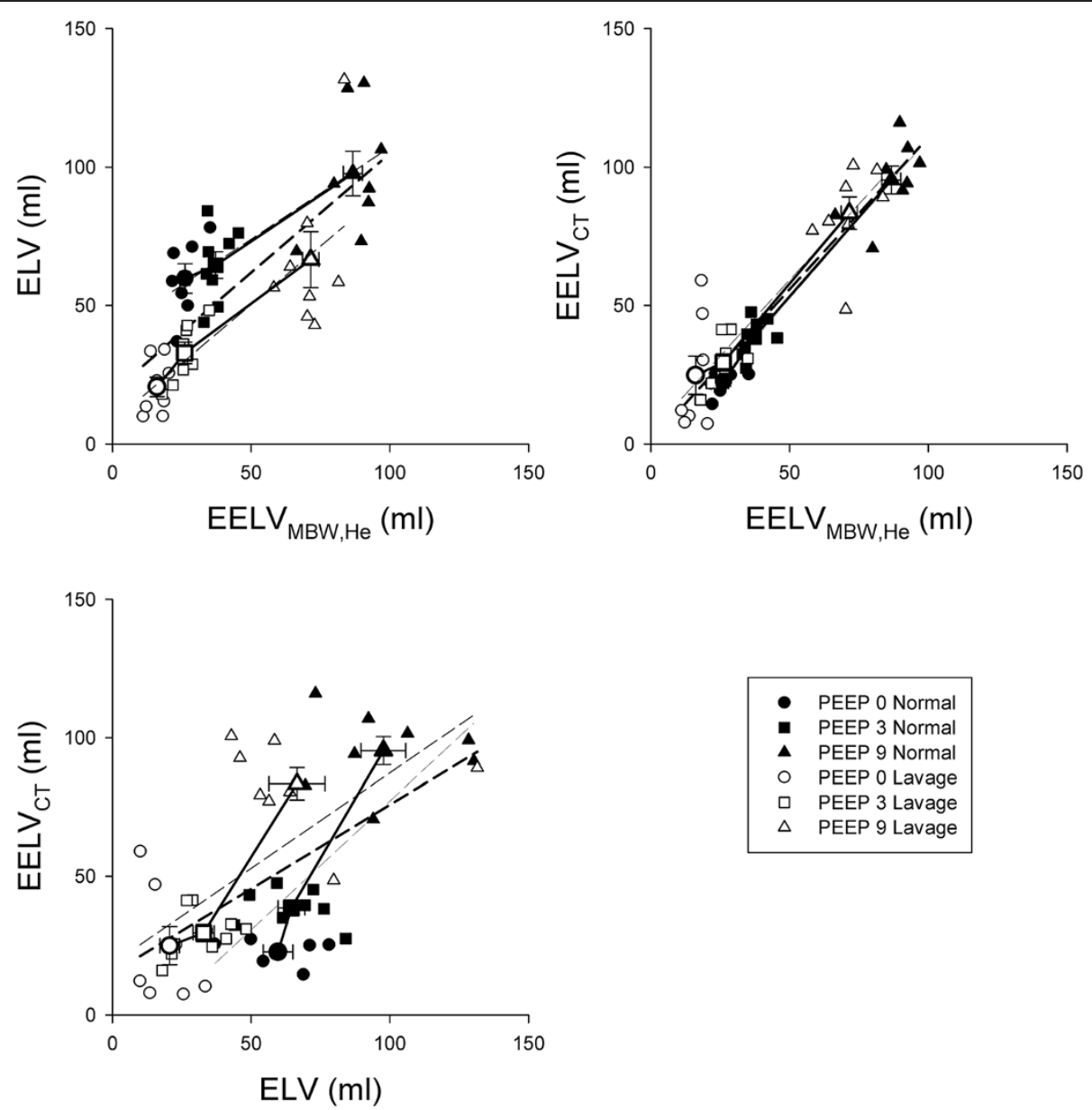

Figure 4 Relationships between pairs of lung volume indices obtained by capnodynamics (ELV), by helium multiple breath washout technique $\left(\mathrm{EELV}_{\mathrm{MBW}, \mathrm{He}}\right)$ and by chest $\mathrm{CT}$-scans $\left(\mathrm{EELV}_{\mathrm{CT}}\right)$. Closed symbols represent lung volume measurements in normal lungs while open symbols denote the values obtained after lavage. Individual values (small symbols) and group mean values (larger symbols) are reported. Dashed lines represent linear regressions with thin lines denoting each condition separately and thick line corresponds to pooled data.

When different lung volume indices and their changes are related, an important feature of their ability to access trapped (non-ventilated) lung regions should be taken into account. Since EELV and ELV are assessed by analyzing the dynamics of the expired gas, these measures provide information only about the size of the ventilated lung regions. Conversely, quantification of lung volume based on chest CT image analyses includes all low attenuation areas and thus, it cannot distinguish between ventilated or trapped aerated regions. This difference is unlikely to affect the lung volume estimates in a normal lungs, however may gain importance after lung lavage where the airway closures may lead to trapped air in the lung periphery. Using a similar experimental model where the regional lung ventilation was assessed by synchrotron imaging, we recently demonstrated that air trapping may be encountered at PEEP level of $3 \mathrm{cmH}_{2} \mathrm{O}$ [17]. Considering that the maximum amount of such lung regions with trapped air does not exceed 10\%, the impact of this phenomenon on our results is minor. Accordingly, we observed no significant difference between the results of the three measurement techniques after lung lavage, despite a trend for a greater EELV lung volume indices that may be explained by this factor (Figure 2, right).

To our knowledge, this is the first study relating lung volume variables obtained by a continuous assessment (ELV) to wash-in/wash-out and imaging techniques in ventilated subjects. A remarkable finding of the present study is the excellent concordance between the lung volume variables obtained by inert gas washout and chest $\mathrm{CT}$ imaging. This was manifested both in the excellent correlations between $\mathrm{EELV}_{\mathrm{MBW}, \mathrm{He}}$ and $\mathrm{EELV}_{\mathrm{CT}}$ (Figure 4) and the good agreement (Figure 5). The importance of this finding stems from the fact that multiple breath washout technique by using ultrasonic flow meter has 

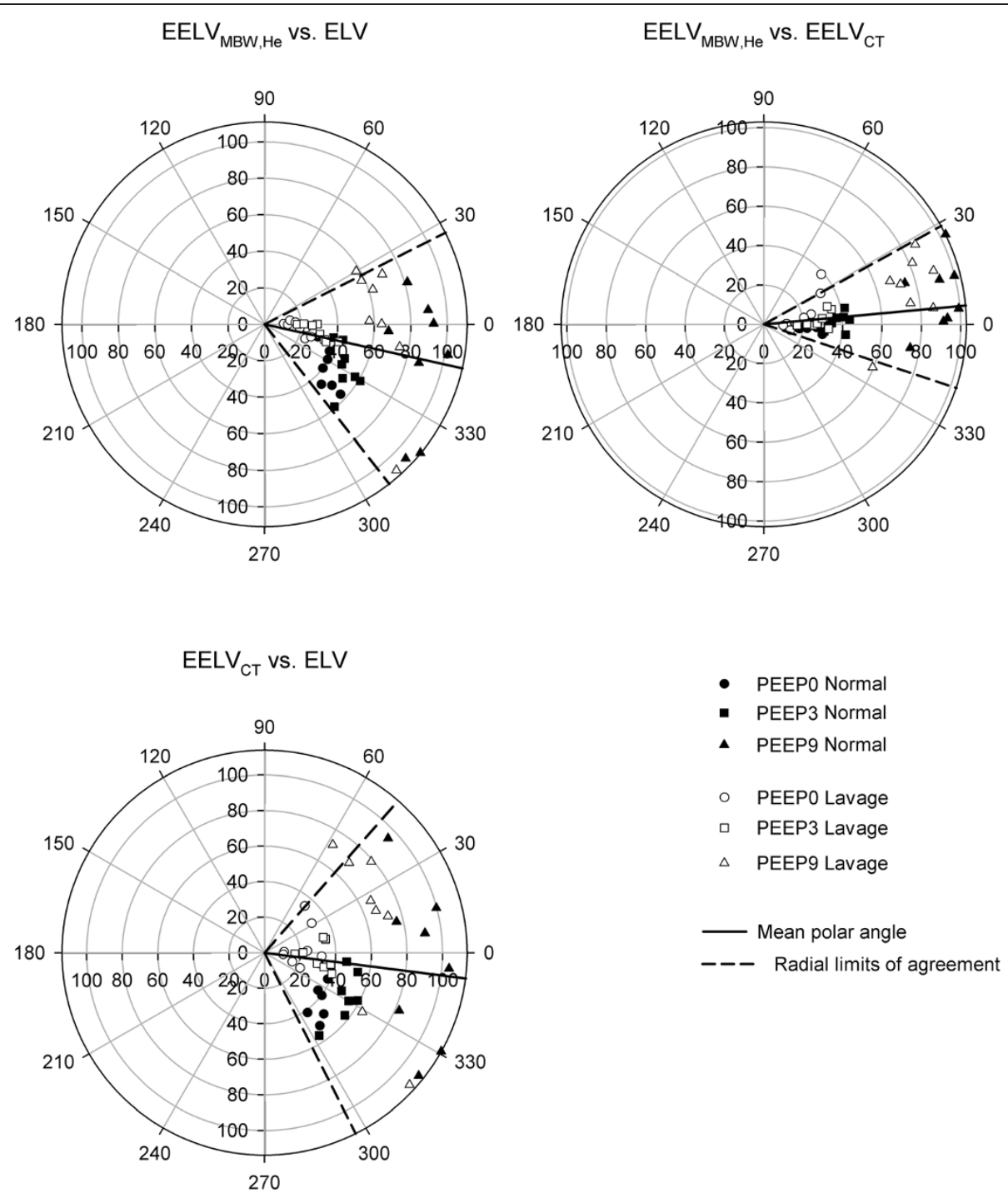

Figure 5 Polar plots demonstrating the degree and the trend of agreements between the lung volume indices. Closed symbols on the left panels represent lung volume measurements in normal lungs while open symbols on the right panels denote the values obtained after lavage. The angle between the radial vector and the horizontal axis represents the magnitude of difference between the corresponding variables (in $\mathrm{ml}$ ), while the distance from the center represents the mean of the two corresponding variables (in $\mathrm{ml}$ ). Solid lines indicate the mean polar angles, while thick dashed lines denote the radial limits of agreements.

been applied commonly in experimental $[6,10,17,20]$ and clinical studies [2,21-26]. However, the relationship of $\mathrm{EELV}_{\mathrm{MBW}, \mathrm{He}}$ obtained by this approach was not related to that obtained by using a reference method in patients with acute lung injury based on CT imaging [7], and the validity of this variable has not been evaluated. Therefore, the results of the present study provides additional evidence on the validity of this ultrasonic tool for monitoring lung volume changes since it provides essentially identical information than the more cumbersome CTimaging. Moreover, the application of the multiple breath wash-out technique gives quantitative information about the magnitude of ventilation heterogeneities, which may be another important variable to guide optimal lung ventilation without the need for the costly imaging involving radiation exposure $[27,28]$.

The advantage of ELV as opposed to the other two lung volume indices is that it allows real-time monitoring of the ventilated lung area available for gas exchange. The results of the present study agree with our previous findings demonstrating that ELV systematically overestimates lung volume measured by inert gas washout in normal lungs at low PEEP levels. This discrepancy disappeared at high PEEP level in normal lungs and was no longer detectable at any PEEP after lung lavage. This divergent relationship resulted in a poorer but significant 
correlation and worsened the agreement between ELV and $\mathrm{EELV}_{\mathrm{MBW}, \mathrm{He}}$ in normal and surfactant depleted lungs (Figures 4 and 5). The novelty of the present study in this regard is the demonstration of a similar relationship of ELV with changes in lung volume computed from chest CT scans. The systematic overestimation of static lung volumes by ELV is most plausibly explained by the contribution of lung capillary blood volume to ELV. Since ELV estimation is based on the analyses of the $\mathrm{CO}_{2}$ as a tracer gas, it comprises the total $\mathrm{CO}_{2}$ content of the lung, which is the sum of the $\mathrm{CO}_{2}$ in the blood and in the alveolar space [6]. Thus, a larger lung volume is expected from the soluble $\mathrm{CO}_{2}$ estimates as compared to a method based on non-soluble tracer gas, such as Helium, which solely measures the alveolar gas volume. Applying an elevated PEEP decreases the capillary blood volume in the pulmonary circulation [19], and this results in a better agreement between ELV and other lung volume indices when high positive pressure is applied in the airways. Furthermore, airway closures induced by surfactant depletion compromises $\mathrm{CO}_{2}$ diffusion into the airspaces, which may explain the improved correlation and closer agreement between ELV and the other lung volume variables in the present of diminished surfactant function. These considerations highlight the potential susceptibility of ELV to alterations in ventilation/perfusion mismatch.

\section{Conclusions}

Lung volume assessment is required to monitor the development of atelectasis and alveolar recruitment and to guide optimal mechanical ventilation. However, lung volume indices that can be obtained bedside have not been related to reference values measured by chest CT scans. Therefore, this study provides meaningful information about the usefulness of bedside monitoring of lung volume to follow its changes with PEEP in normal lungs and in a model of acute lung injury. While lung volume variables obtained by multiple breath washout, $\mathrm{CO}_{2}$ analyses and chest $\mathrm{CT}$ scans indicate lung expansion with increasing PEEP and alveolar derecruitment with lavage, their relationships are variable. Close correlation and excellent agreements were found between lung volumes obtained by He washout and chest CT analyses. However, the association between the effective lung volume achieved by analyzing the dynamics of expiratory $\mathrm{CO}_{2}$ concentration and the other variables proved to be less clear-cut. This may be attributed to methodological differences with particular involvement of the capillary blood volume in the ELV estimates. In conclusion, both bedside techniques offer a valuable tool to follow lung volume changes without the need for cumbersome intervention. However, lung volume monitored by the $\mathrm{CO}_{2}$ tracing provides continuous assessments that are subjected to pulmonary hemodynamical changes, while the $\mathrm{EELV}_{\mathrm{MBW}, \mathrm{He}}$ provides more specific measurements but at a cost of intermittent recordings.

\section{Abbreviations}

$\mathrm{C}_{\mathrm{C}} \mathrm{CO}_{2}$ : Lung capillary $\mathrm{CO}_{2}$ content; $\mathrm{CO}_{2}$ : Carbon dioxide; $\mathrm{CT}$ : Computed tomography; $\mathrm{C}_{\mathrm{V}} \mathrm{CO}_{2}$ : The venous $\mathrm{CO}_{2}$ content; ELV: Effective lung volume; EELV $V_{M B W, H e}$ : End-expiratory lung volume assessed by using multiple-breath washout technique; $E E L V_{C T}$ : End-expiratory lung volume assessed by using chest $\mathrm{CT}$ imaging; $\mathrm{E}_{\mathrm{TCO}}$ : End-tidal $\mathrm{CO}_{2}$ concentration; $\mathrm{F}_{\mathrm{A}} \mathrm{CO}_{2}$ : The alveolar $\mathrm{CO}_{2}$ fraction at end of expiration; $\mathrm{FiO}_{2}$ : Inspired oxygen fraction; He: Helium; HU: Hounsfield Unit; LCl: Lung clearance index; PEEP: Positive end-expiratory pressure; $\mathrm{Q}_{\mathrm{c}}$ : Effective pulmonary blood flow; $\mathrm{VT}_{\mathrm{CO} 2}$ : Volume of $\mathrm{CO}_{2}$ eliminated by one breath; $\Delta \mathrm{t}$ : Time for the breath cycle.

\section{Competing interests}

The laboratory where the experiments were performed received a fund from Maquet Critical Care AB, Solna, Sweden to partially cover the material costs. Mats Wallin, Magnus Hallbäck work at the Research Development Department of the Maquet, Solna, Sweden and they established the theoretical bases of the ELV measurement technique based on capnodynamics. Walid Habre received a research grant from Maquet Solna, Sweden for acting as consultant in the respiratory developments.

\section{Authors' contributions}

GA and TZ carried out the experiments and the preliminary data analyses. FP coordinated the various experimental approaches, and contributed to their design and to the manuscript preparation. MW and $\mathrm{MH}$ participated in the design of the study and in the interpretation of ELV measurements. WH conducted the design of the study and had a major role in drafting the manuscript. All authors have read and approved the final manuscript.

\section{Acknowledgements}

The study was supported by a grant from the Department of Anaesthesiology, Pharmacology and Surgical Intensive Care, Geneva, Switzerland. Ferenc Petak is supported by the TAMOP 4.2.2.A-11/1/KONV2012-0052.

The authors are grateful for the excellent technical assistance of Xavier Belin and Enrique Maturana.

\section{Author details}

'Pathophysiological Experimental Platform, Department of Anaesthesiology, Pharmacology and Intensive Care, University of Geneva, 1 Rue Michel Servet, $\mathrm{CH}-1205$ Geneva, Switzerland. ${ }^{2}$ Department of Medical Physics and Informatics, University of Szeged, 9 Koranyi fasor, H-6720 Szeged, Hungary. ${ }^{3}$ Paediatric Radiology Unit, Department of Radiology and Nuclear Medicine, University Hospitals of Geneva, 6 rue Willy Donzé, CH-1205 Geneva, Switzerland. ${ }^{4}$ Maquet Critical Care AB, Röntgenvägen 2, 17154 Solna, Sweden. ${ }^{5}$ Paediatric Anaesthesia Unit, Geneva Children's Hospital, University Hospitals of Geneva, 6, Rue Willy Donzé, CH-1205 Geneva, Switzerland.

Received: 13 January 2014 Accepted: 1 July 2014

Published: 5 August 2014

\section{References}

1. Schibler A, Henning R: Measurement of functional residual capacity in rabbits and children using an ultrasonic flow meter. Pediatr Res 2001, 49(4):581-588.

2. Pillow JJ, Ljungberg H, Hulskamp G, Stocks J: Functional residual capacity measurements in healthy infants: ultrasonic flow meter versus a mass spectrometer. Eur Respir J 2004, 23(5):763-768.

3. von Ungern-Sternberg BS, Petak F, Hantos Z, Habre W: Changes in functional residual capacity and lung mechanics during surgical repair of congenital heart diseases: effects of preoperative pulmonary hemodynamics. Anesthesiology 2009, 110(6):1348-1355.

4. Olegard C, Sondergaard S, Houltz E, Lundin S, Stenqvist O: Estimation of functional residual capacity at the bedside using standard monitoring equipment: a modified nitrogen washout/washin technique requiring a small change of the inspired oxygen fraction. Anesth Analg 2005, 101(1):206-212. table of contents. 
5. Gedeon A, Krill P, Osterlund B: Pulmonary blood flow (cardiac output) and the effective lung volume determined from a short breath hold using the differential Fick method. J Clin Monit Comput 2002, 17(5):313-321.

6. Albu G, Wallin M, Hallback M, Emtell P, Wolf A, Lonnqvist PA, Gothberg S, Petak F, Habre W: Comparison of Static End-expiratory and Effective Lung Volumes for Gas Exchange in Healthy and Surfactant-depleted Lungs. Anesthesiology 2013, 119(1):101-110.

7. Chiumello D, Marino A, Brioni M, Menga F, Cigada I, Lazzerini M, Andrisani MC, Biondetti P, Cesana B, Gattinoni L: Visual anatomical lung CT scan assessment of lung recruitability. Intensive Care Med 2013, 39(1):66-73.

8. Cressoni M, Gallazzi E, Chiurazzi C, Marino A, Brioni M, Menga F, Cigada I, Amini M, Lemos A, Lazzerini M, Carlesso E, Cadringher P, Chiumello D, Gattinoni L: Limits of normality of quantitative thoracic CT analysis. Crit Care 2013, 17(3):R93

9. Chiumello D, Marino A, Cressoni M, Mietto C, Berto V, Gallazzi E, Chiurazzi C, Lazzerini M, Cadringher P, Quintel M, Gattinoni L: Pleural effusion in patients with acute lung injury: a CT scan study. Crit Care Med 2013, 41(4):935-944

10. Habre W, Scalfaro P, Schutz N, Stucki P, Petak F: Measuring end-expiratory lung volume and pulmonary mechanics to detect early lung function impairment in rabbits. Respir Physiol Neurobiol 2006, 152(1):72-82.

11. Robinson $\mathrm{RH}$ : Ability to detect changes in compliance and resistance during manual artificial ventilation. Br J Anaesth 1968, 40:323-328.

12. Peyton PJ, Venkatesan Y, Hood SG, Junor P, May C: Noninvasive, automated and continuous cardiac output monitoring by pulmonary capnodynamics: breath-by-breath comparison with ultrasonic flow probe. Anesthesiology 2006, 105(1):72-80.

13. Capek JM, Roy RJ: Noninvasive measurement of cardiac output using partial CO2 rebreathing. IEEE Trans Biomed Eng 1988, 35(9):653-661.

14. Bland JM, Altman DG: Statistical methods for assessing agreement between two methods of clinical measurement. Lancet 1986, 1(8476):307-310

15. Critchley $L A$ : Validation of the MostCare pulse contour cardiac output monitor: beyond the Bland and Altman Plot. Anesth Analg 2011, 113(6):1292-1294.

16. Critchley LA, Yang XX, Lee A: Assessment of trending ability of cardiac output monitors by polar plot methodology. J Cardiothorac Vasc Anesth 2011, 25(3):536-546.

17. Bayat S, Porra L, Albu G, Suhonen H, Strengell S, Suortti P, Sovijarvi A, Petak F, Habre W: Effect of Positive End-expiratory Pressure on Regional Ventilation Distribution during Mechanical Ventilation after Surfactant Depletion. Anesthesiology 2013, 119(1):89-100.

18. Brewer L, Orr J, Fulcher E, Markewitz B: Evaluation of a CO2 partial rebreathing functional residual capacity measurement method for use during mechanical ventilation. J Clin Monit Comput 2011, 25(6):397-404.

19. Slutsky RA: Reduction in pulmonary blood volume during positive end-expiratory pressure. J Surg Res 1983, 35(3):181-187.

20. Schibler A, Hammer J, Isler R, Buess C, Newth CJ: Measurement of lung volume in mechanically ventilated monkeys with an ultrasonic flow meter and the nitrogen washout method. Intensive Care Med 2004, 30(1):127-132.

21. Latzin P, Sauteur L, Thamrin C, Schibler A, Baldwin D, Hutten GJ, Kyburz M, Kraemer R, Riedel T, Frey U: Optimized temperature and deadspace correction improve analysis of multiple breath washout measurements by ultrasonic flowmeter in infants. Pediatr Pulmonol 2007, 42(10):888-897.

22. Hulskamp G, Lum S, Stocks J, Wade A, Hoo AF, Costeloe K, Hawdon J, Deeptha K, Pillow JJ: Association of prematurity, lung disease and body size with lung volume and ventilation inhomogeneity in unsedated neonates: a multicentre study. Thorax 2009, 64(3):240-245.

23. Schulzke SM, Hall GL, Nathan EA, Simmer K, Nolan G, Pillow JJ: Lung volume and ventilation inhomogeneity in preterm infants at 15-18 months corrected age. J Pediatr 2010, 156(4):542-549. e542.

24. Sinhal S, Galati J, Baldwin DN, Stocks J, Pillow JJ: Reproducibility of multiple breath washout indices in the unsedated preterm neonate. Pediatr Pulmonol 2010, 45(1):62-70.

25. Landolfo F, Savignoni F, Capolupo I, Columbo C, Calzolari F, Giliberti P, Chukhlantseva N, Bagolan P, Dotta A: Functional residual capacity (FRC) and lung clearance index $(\mathrm{LCl})$ in mechanically ventilated infants: Application in the newborn with congenital diaphragmatic hernia $(\mathrm{CDH})$. J Pediatr Surg 2013, 48(7):1459-1462.
26. von Ungern-Sternberg BS, Petak F, Saudan S, Pellegrini M, Erb TO, Habre W: Effect of cardiopulmonary bypass and aortic clamping on functional residual capacity and ventilation distribution in children. J Thorac Cardiovasc Surg 2007, 134(5):1193-1198.

27. Horsley A: Lung clearance index in the assessment of airways disease. Respir Med 2009, 103(6):793-799.

28. Schibler A, Henning R: Positive end-expiratory pressure and ventilation inhomogeneity in mechanically ventilated children. Pediatr Crit Care Med 2002, 3(2):124-128.

doi:10.1186/1471-2253-14-64

Cite this article as: Albu et al:: Lung volume assessments in normal and surfactant depleted lungs: agreement between bedside techniques and CT imaging. BMC Anesthesiology 2014 14:64.

\section{Submit your next manuscript to BioMed Central and take full advantage of:}

- Convenient online submission

- Thorough peer review

- No space constraints or color figure charges

- Immediate publication on acceptance

- Inclusion in PubMed, CAS, Scopus and Google Scholar

- Research which is freely available for redistribution
C) Biomed Central 